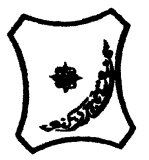

Bayero Journal of Pure and Applied Sciences, 11(2): 81 - 93

Received: July, 2018

Accepted: October, 2018

ISSN 2006 - 6996

\title{
ANALYSIS OF THE PHYLOGENETIC SEQUENCE RELATIONSHIPS BETWEEN PLANT ALPHA AMYLASES
}

\author{
Ibrahim Khalil Adam ${ }^{1 *}$, Bello Aminu Bello ${ }^{1}$, Adam Abdullahi Adam ${ }^{1}$ and Abdullahi \\ Abdulkadir Imam ${ }^{2}$ \\ ${ }^{1}$ Department of Biochemistry, Federal University Dutse, Nigeria \\ ${ }^{2}$ Department of Biochemistry, Bayero University Kano, Nigeria \\ *Corresponding author: ibrahimkhalil_adam@yahoo.com; 07063455543
}

\section{ABSTRACT}

Enzymes are highly valuable in the industry, such industries are food, beverage industry and the biofuel sector. Amylases are very important in starch processing such as liquefaction, hydrolysis and saccharification. Alpha amylase has liquefying ability by hydrolysing the glycosidic bonds at internal positions. This paper aims to present a brief overview of the sequence comparison between plant alpha amylases. The protein sequences were obtained from the NCBI, aligned using the clustal $W$ tool and the phylogenetic trees were constructed using the Mega 7.0 tool. The proteins can be classified into three distinct families; one, two and three. Each family has some peculiar features, family one amylases are proteins of about 450 amino acids long with signal peptides at their $\mathbf{N}$-terminus, family two proteins are similar in size to those of family one but are cytosolic with no targeting peptide. In contrast, family three amylase are proteins targeted to the chloroplast with transit peptides at their N-terminus, however, they are 900 amino acids long. In addition, the last family of protein has an additional domain that is yet to be fully characterized. Across the three families, there is a high homology and thus conservation of the catalytic domain which is at the C-terminus. This implied that the proteins are evolutionary related and perform similar functions. The unknown domain in family three amylases is also conserved across members of this family. The domain may be a starch binding domain that is required for the family three amylases to digest storage starch in the plastid.

Key words: Alpha amylases, Cytosol, Plastid, Family one, Unknown domain

\section{INTRODUCTION}

The amylases are a group of proteins also referred to as glycoside hydrolases or hydrolases (E. C. 3.1) The proteins have a wide range of application such as starch conversion and processing; thus occupy more than thirty percent of the enzyme market worldwide. They are used in food and beverage industries, breweries and the biofuel sector (Kirk, et al., 2002). Structurally, hydrolases differ in their sequence of amino acids, secondary and other higher levels of the proteins, thereby creating variability and dynamism in the protein properties and functions (Henrissat, 1991; Henrissat, et al., 2001; Stam, et al., 2006). Typical examples of the above are the reaction mechanisms, $\mathrm{pH}$ and isoelectric points of the amylases (McCarter and Withers, 1994).

Hydrolases can be classified as endoamylases and exoamylases. The endoamylase break a-1,4 glycosidic bonds in internal positions of the glycans; a-amylase belongs to this class. It hydrolyses the $a-1,6$ glycosidic bonds in polysaccharides such as starch, thus referred to as liquefying enzyme (Kirk, et al,. 2002)bonds at the external part of the starch molecule (Hehre, et al., 1979; Lao, et al., 1999). In contrast, glucoamylase hydrolyses both a-1,4- and a-1,6glycosidic bonds from the external positions of the starch molecule (Kim and Robyt 1999; Sauer, et al., 2000). Thus, it is referred to as a saccharifying enzyme due to its ability to convert dextrins to simple sugars. 
BAJOPAS Volume 11 Number 2 December, 2018 Various researches have focused on the revealing the mode of action of amylases due to their roles in starch processing (Hehre, et al., 1979; McCarter and Withers, 1994). The above in conjugation with the amino acid sequence of the amylases are important in improving the protein functions (Lopez-Casado, et al., 2008; Reilly 1999; Richardson, et al., 2002). Knowledge of the primary structure of the protein is significant in determining protein activity. Elucidating the amino acids at the active site as well as those that affect protein properties such as stability are very paramount (Bessler, et al,. 2003; Cherry and Fidantsef, 2003; Johannes and Zhao 2006; Richardson, et al. 2002). Consequently, the effect of this will facilitate the engineering of the proteins for desirable properties and activities (Eijsink, et al., 2004; Eijsink, et al., 2008; Kelly, et al., 2009).

Amylases have two distinct mechanisms of action; retention and inversion modes. In retention mechanism, the product of hydrolyses retains the a-configuration of starch. Here a single amino acid serves as an acid and a base while another one serves as a nucleophile and a leaving group (McCarter and Withers, 1994). In contrast, the a-configuration of starch is inverted in the second mechanism hence the product has a $\beta$-configuration. An amino acid serves as a general acid and another one acts as a base. Examples of amylases that use retention and inversion mechanisms are a-amylase and beta amylase respectively (McCarter and Withers, 1994). Glu186 and Glu380 residues of $\beta$-amylase from soy bean act as the general acid and base respectively (Kang, et al., 2004).

Alpha-amylase (1,4-a-D-glucan-4glucanohydrolase, EC 3.2.1.1) belongs to the glucosylhydrolase class 13 , the proteins have three domains A, B and C (Kumari, et al., 2010; Kuriki and Imanaka, 1999). The name alpha refers to the configuration at carbon one of the reducing unit of the oligosaccharides generated by the action of the amylase (Chao and Serpe, 2010). It is found in microbes (bacteria and fungi), plants and the archaea; it has has been purified and characterized from $B$. amyloquefaciens (Demirkan, et al., 2005), apple (Stanley, et al., 2002; Wegrzyn, et al,. 2000), malted finger millet (Nirmala and Muralikrishna 2003), banana (Junior, et al., 2006) and soybean (Kumari, et al., 2010) among others. In plants, a-amylase may be produced and secreted by the aleurone cells (in rice) or scutellum (in maize and sorghum) or both into the starch endosperm (do Nascimento, et al.,
2006; Ranki and Sopanen 1984; Warner and Knutson, 1991).

The protein properties such as stability and activity are affected by certain factors. These are high and low pI forms of alpha amylase found on chromosomes 6 and 1 respectively (Mitsui and Itoh 1997). AMY1 and AMY2 of $H$. vulgare are low and high pI of 4.9 and 5.9 forms respectively; thus the optimum $\mathrm{pH}$ of the aamylases is from 4.5 to 5.5 (Robert, et al., 2003; Tibbot, et al., 2002). The optimum temperature of the amylases is between 40 to $55^{\circ} \mathrm{C}$ however in mature seed germinated at much lower temperatures therefore thermal stability is not important (Prakash and Jaiswal, 2010). High temperatures above $60^{\circ} \mathrm{C}$ may lead to inactivation of these proteins with a few exception as observed in the brewing variety of barley a-amylase which can withstand temperature of $65^{\circ} \mathrm{C}$ (Prakash and Jaiswal, 2010). Some a-amylases require calcium for their stability, and activity (Tanaka and Hoshino, 2002; Tanaka and Hoshino, 2003).

Glycosylation which is the addition of glycans, a process that takes place in the endoplasmic reticulum (Vitale and Denecke, 1999). It affects protein activity, stability and functions (de Barros, et al., 2009; Motyan, et al., 2011). Oglycosylation involves glycan addition at hydroxyl groups of serine and threonine residues; while in $\mathrm{N}$-glycosylation the addition is on asparagine residues of the sequence Asn-XSer/Thr. The role of the glycosylation is not clear (Motyan, et al., 2011; Vitale and Denecke, 1999). This work is aimed at establishing the relationships between plant amylases.

\section{METHODOLOGY}

\section{Retrieval of a-amylase Sequence}

The protein sequences of various plants aamylases were obtained from the NCBI databases (http://www.ncbi.nlm.nih.gov/). Amino acids sequences of the following plants aamylases were retrieved: Hv (H. vulgare), In (I. nil), Pv ( $P$. vulgaris), Gm (G. max), Vm ( $V$. mungoculata), $\mathrm{Sb}$ ( $S$. bicolor), $\mathrm{Md}$ ( $M$. domestica), $\mathrm{Ma}$ ( $M$. acuminata), Me ( $M$. esculanta), At ( $A$. thaliana), Vv ( $V$. vinifera), St ( $S$. tuberasum), Ot ( $O$. taurii), Ac ( $A$. chinensis), and $\mathrm{Rc}(R$. communis). The sequences were subject to in silico and bioinformatics analysis as described below.

\section{Alignment of amino sequences of plant a- amylases}

The alignments of the proteins were performed using publicly available database at EBI. The sequences were aligned using the BLOSUM62 algorithm with the ClustalW alignment tool. 
The full protein sequences, the C-terminal (domain) sequences only and $\mathrm{N}$-terminal (domain) sequences only in some instances were aligned to determine the homology and relationships between the respective plant amylases

\section{Phylogenetic Analysis}

Phylogenetic trees of plant alpha amylases showing the evolutionary relationship between plant a-amylases were constructed using protein sequences obtained from the publicly available data (http://www.ncbi.nlm.nih.gov/). The sequences were aligned using the ClustalW alignment tool. The aligned sequences were assembled into a phylogenetic tree using the boot-strapped neighbor-joining algorithm (Saitou and Nei 1987) and the Jones-Taylor-Thornton amino acid substitution model (Jones, et al., 1992) in MEGA 7.0 with 1000 trials (http://www.megasoftware.net/) (Tamura, et al., 2011). Bootstrap values are indicated as percentages of the 1000 trials at their respective node.

\section{RESULTS AND DISCUSSION Classification of Plant a-amylases and Phylogenetic Relationship}

In order to review the relationship between plant a-amylases; In silico and bioinformatic tools were used. The protein sequences of the amylases belonging the three families were retrieved from the National Centre for Biotechnology (NCBI) database. In order to understand in greater details, the sequence homology between the amylase, one representative of each family was chosen. The sequences were subjected to multiple alignment using ClustalW at EBI. The alignment is shown in Figure 1, different homologies were observed between the different families. The family I and II a-amylases are more closely related to each other, but more distantly related to family III aamylases.

The alignment indicated that certain amylases have longer sequences compared to the others. These sequences are in between the $\mathrm{N}$-terminus and C-terminus of the proteins of about 450 amino acids, hence the need to understand the relationship between the proteins. Members of the three families were used to construct a phylogenetic tree. The dendogram is shown in Figure 2 below, it indicated closer relationship between family one and two amylases compared to family three as was shown by the alignment (Figure 1). Family two a-amylase may likely be the ancentral origin of plant alpha amylases from which other types evolved.

There are various types of classification for the plant a-amylases based on the tissues they are found (Huang, et al., 1992; Mitsui and Itoh 1997). A popular classification for plant aamylases is based on the cellular localisation of the proteins. The amylases are grouped into three distinct families; one, two and three (Janecek 2002; Stanley, et al., 2002). Family one a-amylases contain signal peptides that target the proteins to endoplasmic reticulum. The second family are the cytosolic a-amylases that do not have any targeting peptide (Janecek, 2002; Stanley et al., 2002). Family three amylases have transit peptide and are localised to the plastid (chloroplast) (Stanley, et al. 2005; Stanley, et al., 2002).. The three families differ in the size of proteins, family one and two aamylases are smaller while family three amylases are twice size. 
BAJOPAS Volume 11 Number 2 December, 2018

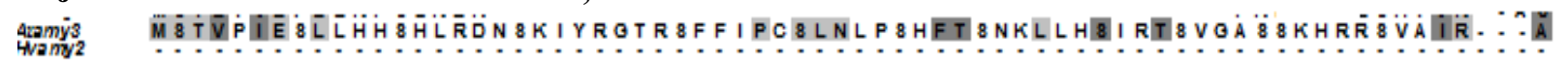

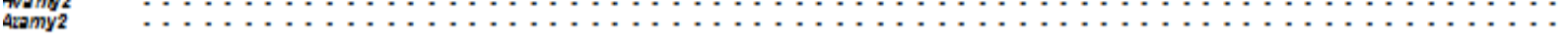

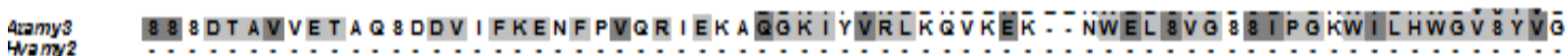

Wrany 2

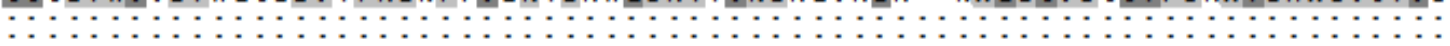

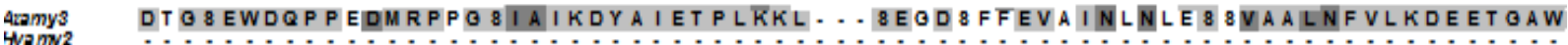

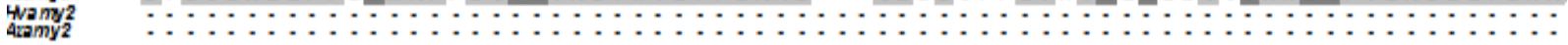

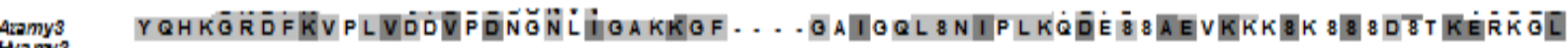

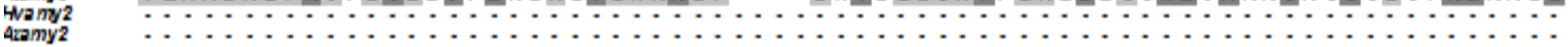

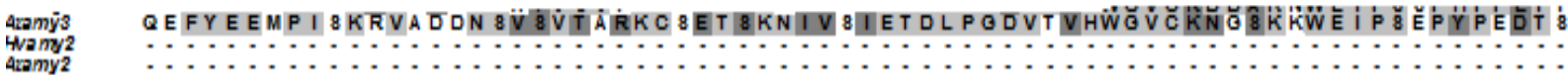

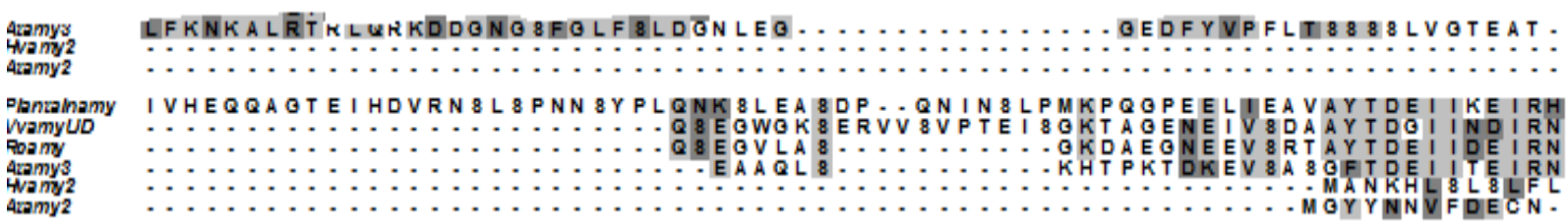

4ZEMYS LAIDIH8HKNQKTNVKEVQENILQEIEKLAAEAY8IFR8TTPTFBEE

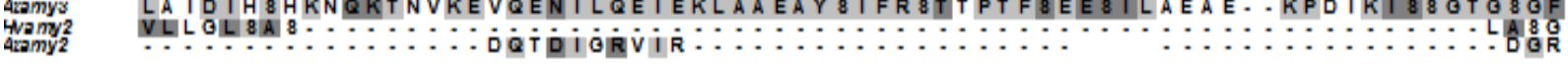

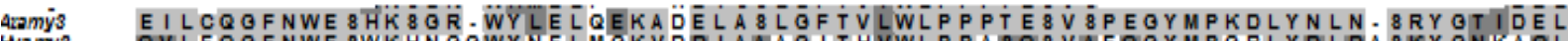

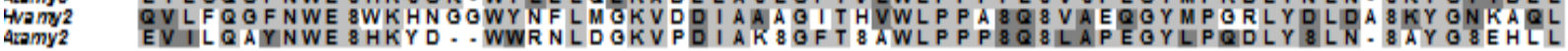

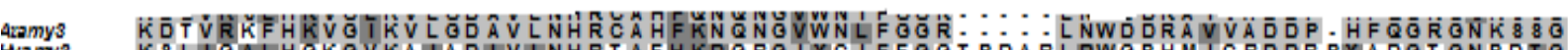

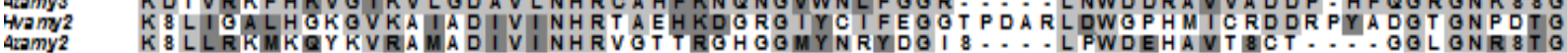

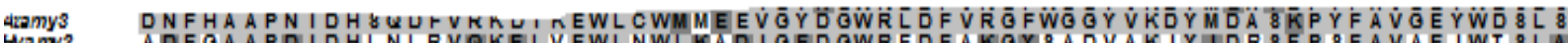
WVmy2
Aramy2

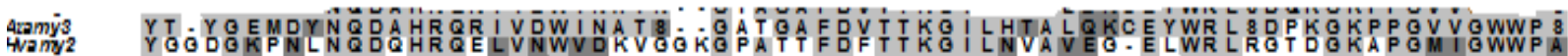

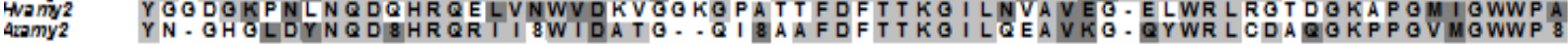

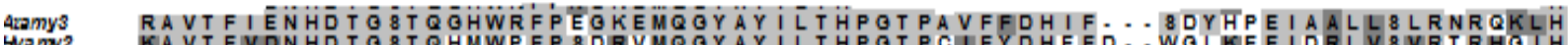
KEAmY2

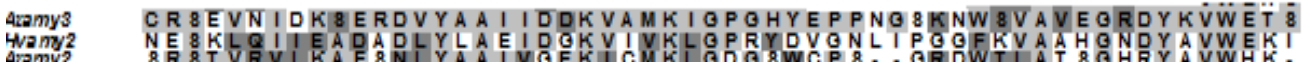

Figure 1 An alignment of representative of the three families. Protein sequences were obtained using publicly available data (http://www.ncbi.nlm.nih.gov/), aligned using the BLOSUM62 algorithm with the ClustalW alignment tool. Family I is represented by Hvamy2, family II represented by Atamy2 and family three represented by Atamy3. Grey = conserved residues. 


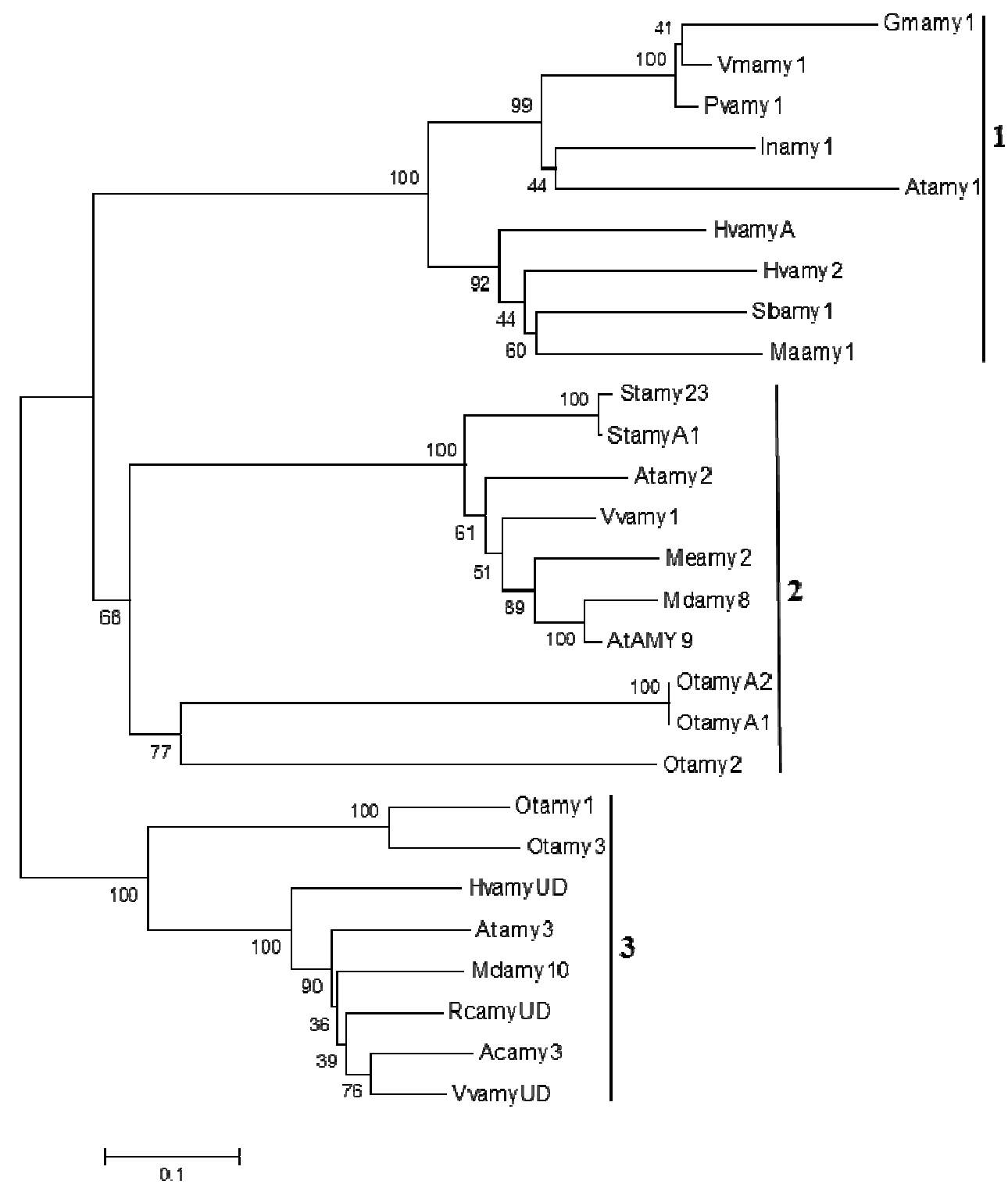

Figure 2. Phylogenetic tree of plant alpha amylases showing the evolutionary relationship between plant a-amylases. Protein sequences were obtained using publicly available data (http://www.ncbi.nlm.nih.gov/), aligned using the ClustalW alignment tool. The aligned sequences were assembled into a phylogenetic tree using the boot-strapped neighbor-joining algorithm (Saitou and Nei 1987) and the Jones-Taylor-Thornton amino acid substitution model (Jones, et al. 1992) in MEGA 7.0 with 1000 trials (http://www.megasoftware.net/) (Tamura, et al. 2011). Bootstrap values are indicated as percentages of the 1000 trials at their respective node. Abbreviatios: $\mathrm{Hv}$ (H. vulgare), In (I. nil), Pv (P. vulgaris), Gm (G. max), Vm (V. mungoculata), Sb (S. bicolor), Md (M. domestica), Ma (M. acuminata), Me (M. esculanta), At (A. thaliana), Vv (V. vinifera), St (S. tuberasum), Ot (O. taurii), Ac (A. chinensis), Rc and (R. communis). 1, 2 and 3 represents family one, two and three respectively. Establishing Sequence Homology between
Family One and Two Amylase

Following the alignment shown in Fig. 1 and the dendogram in Fig. 2, a close relationship between family one and two amylases was observed. To analyse and confirm the homology between the proteins; amylases from the two families were aligned using ClustalW and is shown in Figure 3. 
BAJOPAS Volume 11 Number 2 December, 2018

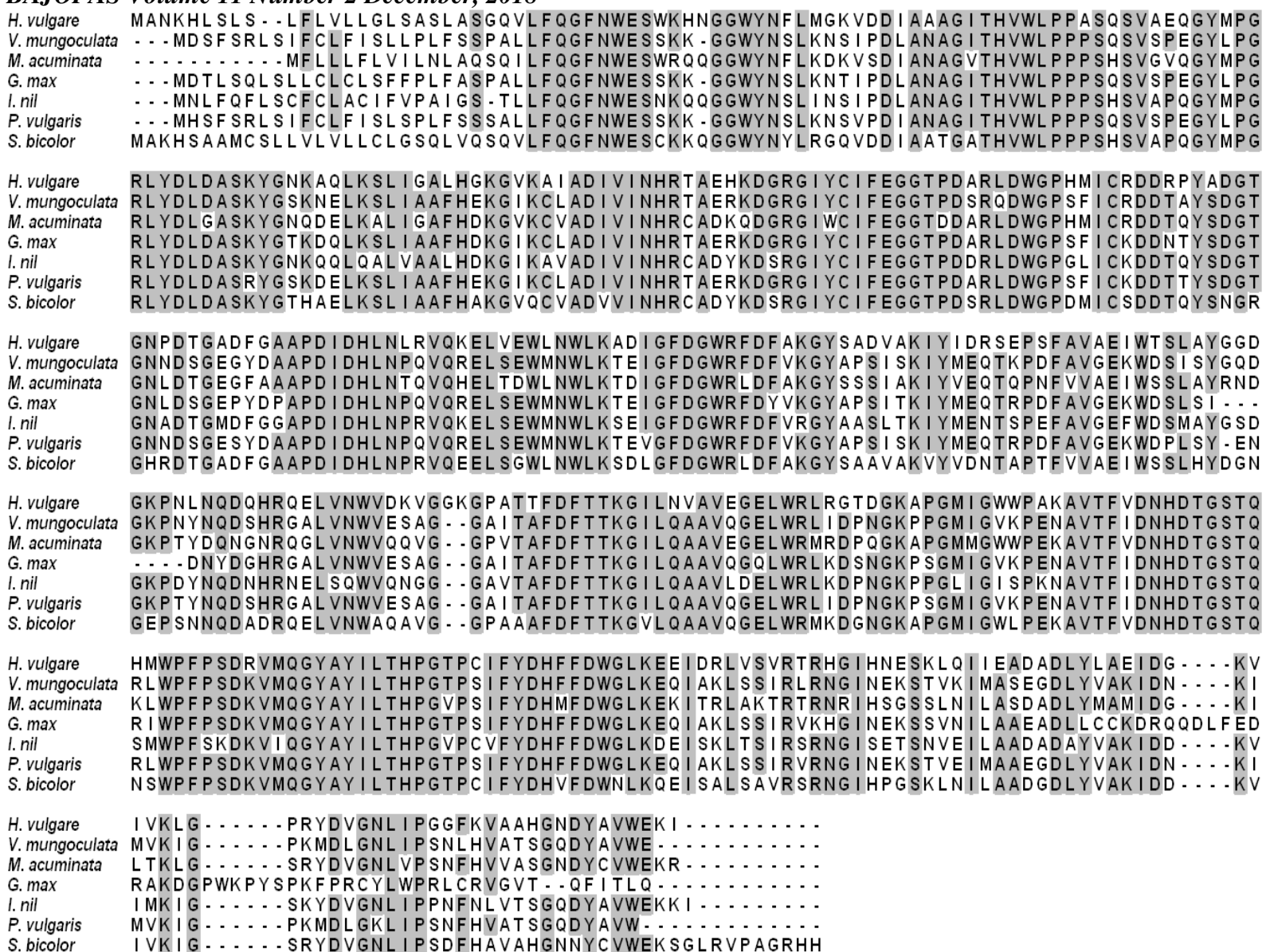

Figure 3 Sequence conservation of Family One \& two amylases. Shows the alignment of amino acid sequences of a-amylases from, $\mathrm{Hv}=$ Hordeum vulgare, $\mathrm{Vm}=$ Vigna mungo, $\mathrm{Ms}=$ Musa specie, $\mathrm{Gm}=$ Glycine max, In= Ipomea nil, $\mathrm{Pv}=$ Phaseolis vulgaris, $S b=$ Sorghum bicolour. Grey= conserved residues. No conservation in the signal peptide, but some areas with good sequence conservation were observed.

\section{Conservation in the Catalytic Domain across Plant Alpha Amylases}

It was observed that the amylases have lots of variability in the $\mathrm{N}$-terminus, but high homology in the C-terminus, where the protein activity resides (also referred to as catalytic or amylase domain). In order to investigate the conservation in this domain, the C-terminus of amylases were subject to alignment using clustalW. Figure 4 shows the alignments, the homology in the C-terminus is quite striking with little variation in the amino sequences. More than $80 \%$ homology was observed between the plant amylases in the catalytic region or Cterminus. 
BAJOPAS Volume 11 Number 2 December, 2018

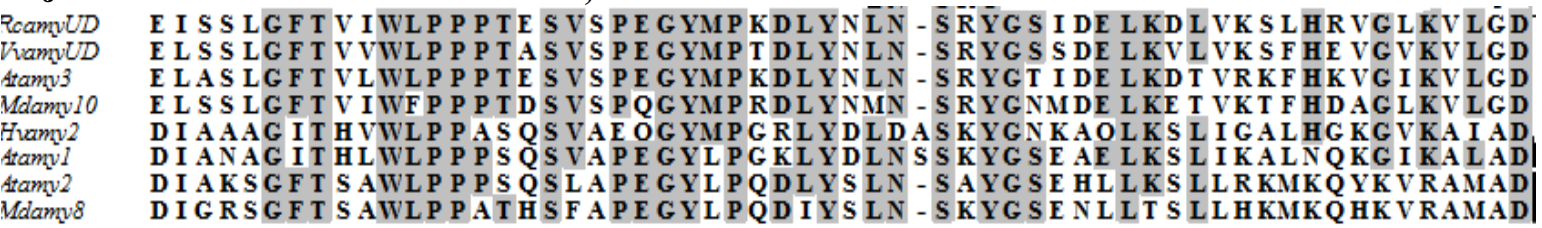

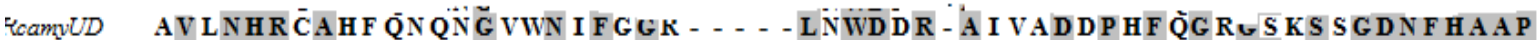

AVIHRCAYQQNG IWN I FGG

Atamy 3 AVLNHRCAHFKNQNG VWNLFGGR - - - L NWDDR - AVVADDPHFQGRGNKS SGDNFHAAP

tham 3 AVLNHRCAE YQNQNG VWN I FGGR - - - L NWDER - AVVADDPHFQG RGNKSSGDSFHAAP IVINHRTAE HKDGRG IYCIFEGGT PDARLDWG PHMICRDDRPYADGTGNPDTGADFGAAP IVINHRTAERKDDKCGYCYFEGGT SDDRLDWDP SFVCRND-PKF PGT GNLDTGGDF DGAP

Atamy2 IV I NHR VGT TRG HGGMYNRYDG IS - . - L PWDE H - AVT SCT - . GGLGNRSTGDNFNG VP

Melang IVINHPVGT TRGHGGKYNRYDG IS - - - L SWDER - AAT S CT - - GGLGNPSTGDNFHG VP

RcamyUD
ViamyUD
Atamy3
Mdamy10
Huamy2
Atamy1
Atamy2
Mdamy 8

N I DHSODF VRODLKEWL CWLRDE IGYNGWRLDFVRG FWG GYVKDYMËT̄ T PYFAVGE YWD NI DHSODF VRE D I KE WL CWLRKE I GYDGWRLDF VRG FWG G YVKDYMDASE P YFA VGE YWD N I DHSODF VRKD IKE WL CWMME E VG YGWRLDF VRG FWG G YVKDYMDA S K P Y A A GE YWD N I DHSQDF VRKD IRE WL CWLRDD I GYDGWRLDF VRG FWG GYVKDYMDASE PYFAVGE YWD D I DHLNLRVQKE LVE WL NWLKAD I GFDGWRF DFAKG Y ADVAK IY I DR SE P SFAVAE IWT DI DHLN P R VOKE L SE WMNWLKTE I G F HGWR F DYVRG YAS S I T KLYVONTS P DFA VGE KWD NVDHT OHF VRKD I I GWLRWLRNT VGFQDFRF DFARG YSANYVKEY I GAAKPLF S VGE CWD NIDHSQLFVRKD I T GWLQWLRNN VGFQDFRF DFARG Y S A KVKEYIE GAKP I F S VGE YWD

RcamyUD
VuamyUD
Atamy3
Mdamy10
Huamy2
Atamy1
Atamy2
Mdamy 8

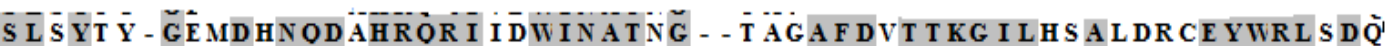
S L S YT Y - GEMDHNODAHROR I I DWINAT NG - AAGAFDVT TKG ILHSALGRCEYWRLSDQ S L SYT Y - GEMDYNODAHROR I VDWINATSG - A T GA F DVT TKG I LHTALQKCEYWRLSDP S L SYT Y - GEMDHNODAHROR I VDWINAT NG - - T CGA F DVT T KG I LHAALERCEYWRLSDE SLAYGG DGK P L NODOHROE LVNWVDKVGGKG PAT T F DFT T KG I LN VAVEG - E LWRLRGT DMKYGG DGKLDYDONEHRSG LKQWIE E AGG - GVLT A F DF T T KG I LQSAVKG - E LWRLKDS SCNYNG - HGLDYNODSHROR I ISWIDATGQ - - I SAAF DFT TKG ILQEAVKG - QYWRLCDA SCNYNG - HG LDYTQDSHRQPIVNWINGTGQ - L T A F T TKG ILQEAVKG - QLWRLRDP

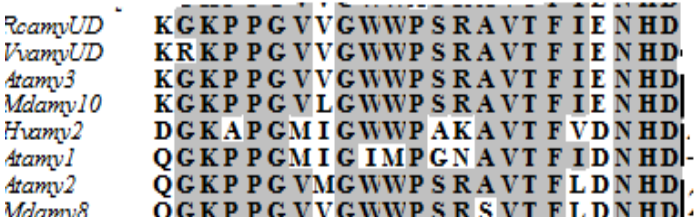

Figure 4 Alignment of C-terminus of some amylases clustalw alignment of amino acid sequence of aamylases from the three families. Family 3: RcamyUD (R. communis), VvamyUD (V. vinifera), Atamy3 and Mdamy10, family 2: Atamy2 and Mdamy8 (apple) and family 1: Hvamy2 (H. vulgare) and Atamy1 (Arabidopsis); Grey areas represent conserved regions.

The amino acid residues in the catalytic region are highly conserved among the plant aamylases. This implied that the proteins carry similar and related function. In addition to the homology observed in Figure 4 above, it became imperative to subject the C-terminus of the proteins from the three families to phylogenetic analysis. Figure 5 is a dendogram constructed using amino acid sequence of the C-terminus alone. The tree showed similar pattern and relationship to that shown in Figure 2, it further confirmed the classification of amylases into three families and that family one and two proteins are closer to each other, than to amylases of family three. 


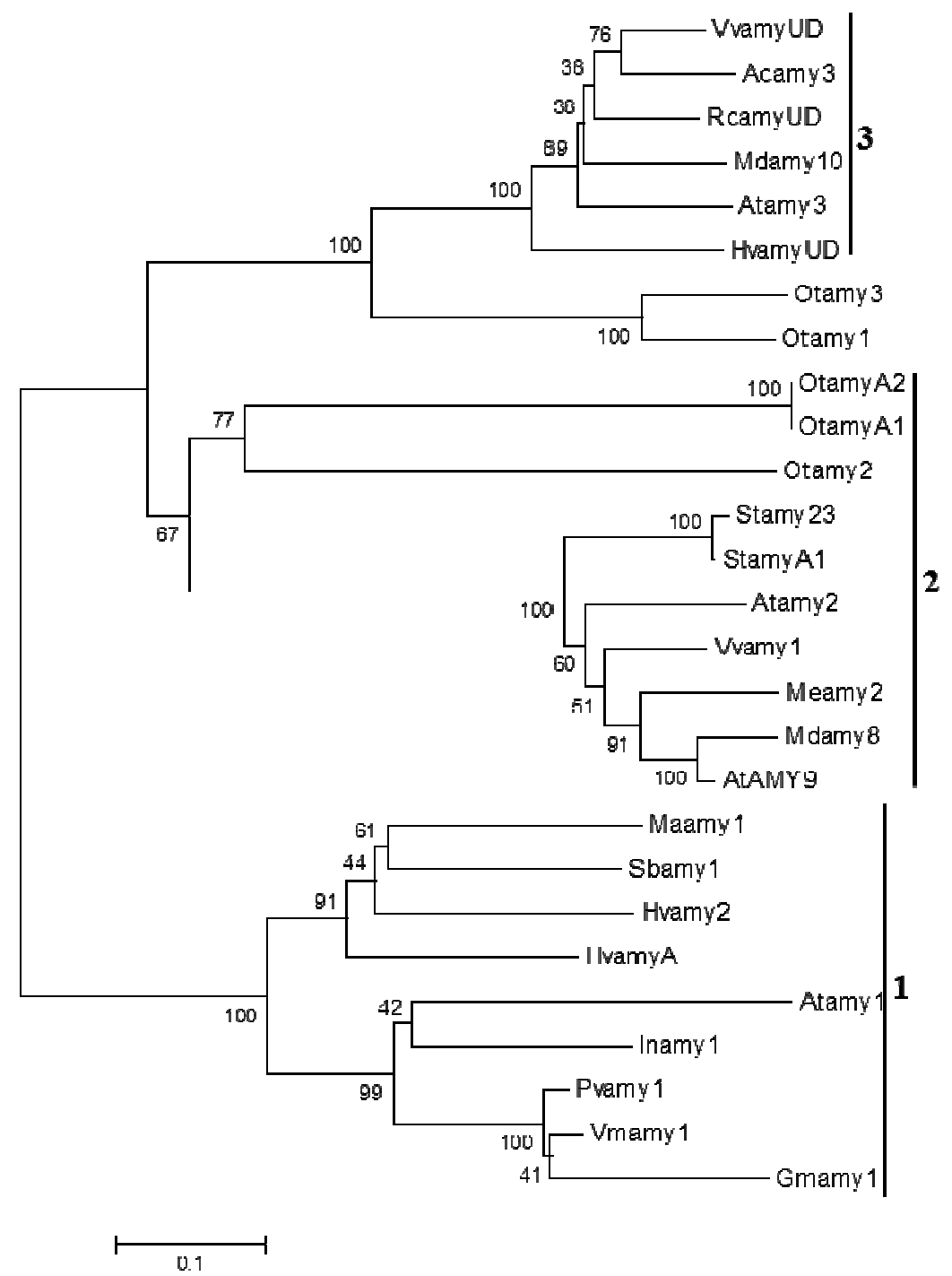

Figure 5 Phylogenetic tree of C-terminus of plant alpha amylases showing the evolutionary relationship using only the catalytic domain for comparison. All other details are as described in Figure 2.1, 2 and 3 represents family one, two and three respectively.

\section{Conservation in the Unknown Domain of family 3 amylases}

The family three amylases have a large $\mathrm{N}$ terminal domain of yet to be established function, the domain starts after the transit peptide and ends with a linker region (GTGSG). The linker connects the unknown domain to the rest part of the protein which is the amylase domain. There may be conservation of amino sequence of this regions between the proteins. In order to obtain evidence, protein sequences corresponding to the 500 amino acids from six different type 3 a-amylases were aligned using clustalW2. Figure 6 reveals the degree of conservation in the $\mathrm{N}$-terminal unknown domain of family 3 proteins. Significant conservation between the different proteins in the additional domain was observed. However, there are some regions in the domain that are not conserved across the group. This is not uncommon as it is often the case in large family of proteins. 
BAJOPAS Volume 11 Number 2 December, 2018

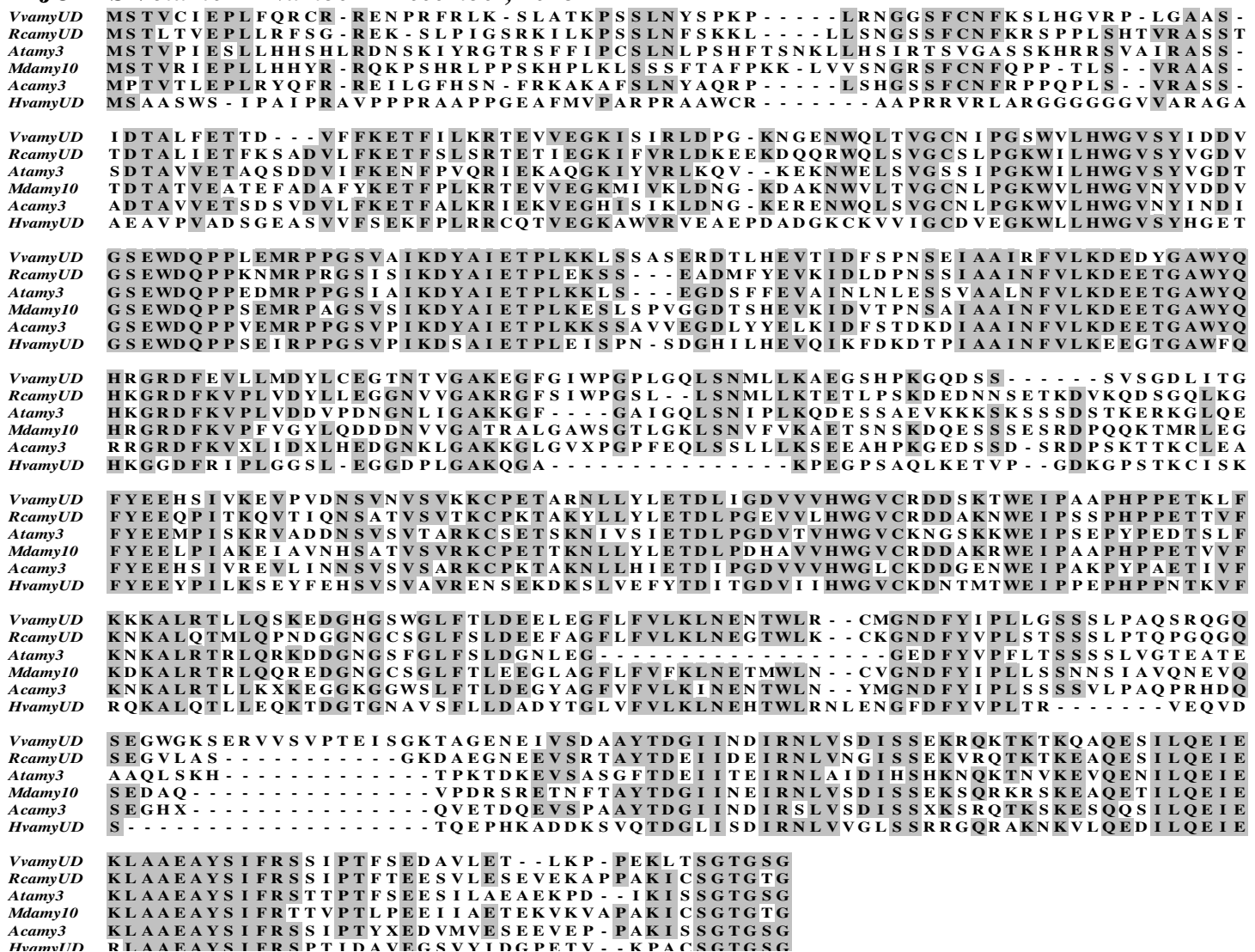

Figure 6. Conservation of the unknown domain in family three a-amylases, an alignment of the some of the family three a-amylases is shown. Areas in grey indicate amino acids that are conserved in the family three proteins.

Furthermore, in order to have conclusive evidence, a phylogenetic tree, Figure 7 shows the dendogram produced of the unknown domain only and the full proteins respectively.

The trees further established and confirmed the relationships revealed by the alignment in Figure 6.

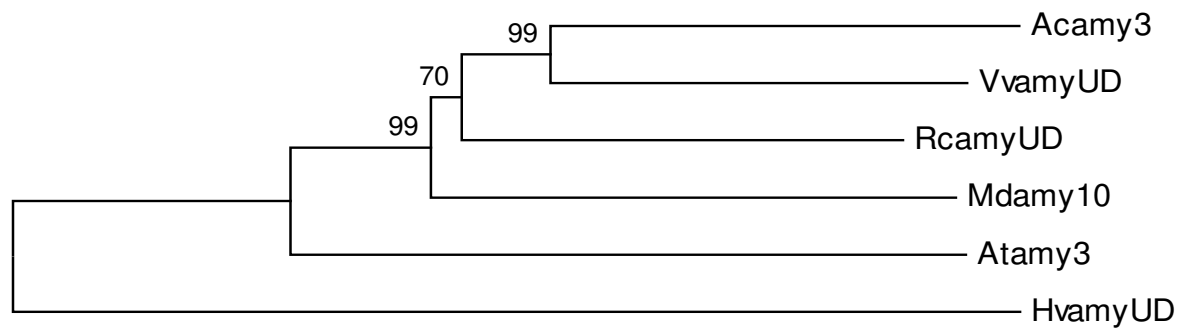

0.05

Figure 7. Phylogenetic tree of family three amylases showing the evolutionary relationship between them. The full protein sequence of about 900 amino acids were. Protein sequences were obtained using publicly available data (http://www.ncbi.nlm.nih.gov/), aligned using the ClustalW alignment tool. The aligned sequences were assembled into a phylogenetic tree using the boot-strapped neighbor-joining algorithm (Saitou and Nei 1987) and the Jones-Taylor-Thornton amino acid substitution model (Jones, et al. 1992) in MEGA 7.0 with 1000 trials (http://www.megasoftware.net/) (Tamura, et al. 2011). Bootstrap values are indicated as percentages of the 1000 trials at their respective node. Abbreviatios: Ac (A. chinensis), Vv (V. vinifera), Rc ( $R$. communis), Md (M. domestica), At (A. thaliana) and Hv (H. vulgare). 


\section{Perspectives and Conclusion}

The a-amylases are proteins of invaluable functions in plants, they are involved in the hydrolysis of starch. This is in addition to their significant roles in industrial starch processing (Adam, et al., 2017). Lots of experimental evidence support this view, the function of the amylases were deduced by generating mutants. In germinating cereal endosperm, a secreted saamylase converts starch to linear and branched glucans (Beck and Ziegler, 1989; Kotting, et al., 2010). The oligosaccharides are hydrolysed further by the actions of enzymes; limit dextrinase attacks the a-1,6 linkages and while $\beta$-amylase hydrolyse the linear oligosaccharides from the ends. Maltose and glucose are released; and are exported to the scutellum. Similarly, the same process occurs in ripening fruits. Maltose may be converted to sucrose through the glucose 1-phosphate pathway. This is also supported further by the fact that only trace amounts of maltose are found in ripening fruit (Fioravante Bernardes Silva, et al., 2008; Hill and Aprees 1994; Prabha and Bhagyalakshmi, 1998).

High activity of a-amylase has been reported during seed germination. This indicates its role in starch mobilization in germinating seeds where starch reserves are used for energy (Irving, et al., 1999; Zeeman, et al., 2010). The synthesized a-amylase in the aleurone and scutellum is secreted into the endosperm to degrade starch. Thus, a-amylase plays a principal role in starch hydrolysis in the endosperm during germination (James, et al., 2009; Kumari, et al., 2010). Although a-amylase plays an important role in storage starch hydrolysis in the endosperm, it may not be involved in transitory starch hydrolysis in the chloroplasts of leaves. An Arabidopsis mutant (designated as sex4 mutant) with low a-amylase activity showed normal trend of starch metabolism compared to the wild type. It is also evident that mutation in $A M Y 3$ that is present in the chloroplast does not change the rate of starch hydrolysis in leaves (Yu, et al., 2005; Zeeman, et al., 2007a \&b). Thus alpha-amylase may be less significant in transitory starch breakdown.

\section{REFERENCES}

Adam, I. K., et al. (2017) Purification of an Alpha amylase like Protein from Plantains. Journal of Advances in Biology and Biotechnology 14(4): 1-8
Family one amylase such as Hvamy2 are secreted proteins with signal peptide for translocation across the ER membrane. In the cytosol, the SP of this soluble protein is recognised by signal recognition particle (SRP) and is cleaved by the signal peptide peptidase (SPP) (Lyko, et al., 1995; Walter and Blobel, 1981; Weihofen, et al., 2002). They are found in cereals and seeds of dicot plants. This family of enzymes has also been described to be involved in the degradation of extracellular starch and can be found in microbes. The presence of this type of protein in seeds of higher plants may be due to the need of the enzyme to translocate across membranes to the specialised starch tissues such as the endosperm in cereals (Stanley, et al., 2005; Stanley, et al., 2002). The second family of alpha amylase consists of proteins that localise to the cytoplasm due to the absence of any characterised targeting peptide. They are found in leaves of monocots and dicot plants as well as gymnosperms. This group of enzymes degrade cytosolic a-glucan or heteroglycan (Stanley, et al., 2005; Stanley, et al., 2002). Family three a-amylases have a chloroplast transit peptide with a large $\mathrm{N}$ terminal domain in addition to the a-amylase domain considered to be starch binding domain (Stanley, et al., 2005; Stanley, et al., 2002).

In conclusion, starch is semi-crystalline in nature of starch hence enzymes of starch degradation have properties to enable effective and strong binding to the substrate leading to hydrolysis. This can be a specific substrate binding site in the catalytic domain of the enzyme or a carbohydrate binding module (CBM) or starch binding domain (SBD) ) (Chou, et al., 2010; Machovic and Janecek 2006b; Rodriguez-Sanoja, et al., 2005) (Glaring, et al., 2011; Janecek, et al., 2011; Machovic and Janecek 2006). This implied that the proteins are evolutionary related and perform similar functions. The unknown domain in family three amylases is also conserved across members of this family. The domain may be a starch binding domain that is required for the family three amylases to digest storage starch in the plastid.

Beck, E., and Ziegler, P. (1989) Biosynthesis and degradation of starch in higher plants. Annual Review of Plant Physiology and Plant Molecular Biology 40:95-117. 
BAJOPAS Volume 11 Number 2 December, 2018

Bessler, C., et al., (2003) Directed evolution of a bacterial alpha-araylase: Toward enhanced $\mathrm{pH}$-performance and higher specific activity. Protein Science 12(10):2141-2149.

Chao, W. S., and Marcelo D. S. (2010) Changes in the expression of carbohydrate metabolism genes during three phases of bud dormancy in leafy spurge. Plant Molecular Biology 73(12):227-239.

Cherry, J. R., and Fidantsef, A. L. (2003) Directed evolution of industrial enzymes: an update. Current Opinion in Biotechnology 14(4):438-443.

Chou, Wei-Yao, et al. (2010) Featureincorporated alignment based ligandbinding residue prediction for carbohydrate-binding modules. Bioinformatics 26(8):1022-1028.

de Barros, Manoel Cardoso, et al., (2009) The influence of $\mathrm{N}$-glycosylation on biochemical properties of Amy1, an alpha-amylase from the yeast Cryptococcus flavus. Carbohydrate Research 344(13):1682-1686.

Demirkan, E. S., et al., (2005) Alpha-amylase from $B$. amyloliquefaciens. purification, characterization, raw starch degradation and expression in E-coli. Process Biochemistry 40(8):2629-2636.

do Nascimento, J. R. O., et al., (2006) Betaamylase expression and starch degradation during banana ripening. Postharvest Biology and Technology 40(1):41-47.

Eijsink, V. G. H., et al., (2004) Rational engineering of enzyme stability. Journal of Biotechnology 113(1-3):105-120.

Eijsink, V. G. H., et al., (2008). Towards new enzymes for biofuels: lessons from chitinase research. Trends in Biotechnology 26(5):228-235.

Fioravante Bernardes Silva, Ana Paula, et al. (2008) Starch mobilization and sucrose accumulation in the pulp of Keitt mangoes during postharvest ripening. Journal of Food Biochemistry 32(3):384395.

Glaring, Mikkel A., et al., (2011) Starch-binding domains in the CBM45 family - lowaffinity domains from glucan, water dikinase and alpha-amylase involved in plastidial starch metabolism. Febs Journal 278(7):1175-1185.
Hehre, E. J., C. F. Brewer, and D. S. Genghof (1979) Scope and mechanism of carbohydrase action - hydrolytic and non-hydrolytic actions of beta-amylase on alpha-maltosyl and beta-maltosyl fluoride. Journal of Biological Chemistry 254(13):5942-5950.

Henrissat, B. (1991) A classification of glycosyl hydrolases based on amino acid sequence similarities. Biochemical Journal 280:309-316.

Henrissat, B., P. M. Coutinho, and G. J. Davies (2001) A census of carbohydrate-active enzymes in the genome of Arabidopsis thaliana. Plant Molecular Biology 47(12):55-72.

Hill, S. A., and T. Aprees (1994) Fluxes of carbohydrate metabolism in ripening bananas. Planta 192(1):52-60.

Huang, N., G. L. Stebbins, and Rodriguez R. L. (1992) Classification and evolution of alpha amylase genes in plants. Proceedings of the National Academy of Sciences of the United States of America 89(16):7526-7530.

Irving, D. E., G. J. Shingleton, and P. L. Hurst (1999) Starch degradation in buttercup squash (Cucurbita maxima). Journal of the American Society for Horticultural Science 124(6):587-590.

James, Martha G., et al., (2009) Identification and characterization of a novel alphaamylase from maize endosperm: Iowa State University Research Foundation Inc.

Janecek, S. (2002) How many conserved sequence regions are there in the alphaamylase family? Biologia 57:29-41.

Janecek, Stefan, Birte Svensson, and Ann MacGregor E. (2011) Structural and evolutionary aspects of two families of non-catalytic domains present in starch and glycogen binding proteins from microbes, plants and animals. Enzyme and Microbial Technology 49(5):429440.

Johannes, T. W, and Zhao H. M. (2006). Directed evolution of enzymes and biosynthetic pathways. Current Opinion in Microbiology 9(3):261-267.

Jones, D. T., Taylor, W. R., and Thornton J. M. (1992) The rapid generation of mutation data matrices from protein sequences. Computer Applications in the Biosciences 8(3):275-282. 
BAJOPAS Volume 11 Number 2 December, 2018

Junior, A. V., do Nascimento, J. R. O and Lajolo F. M. (2006) Molecular cloning and characterization of an alpha-amylase occuring in the pulp of ripening bananas and its expression in Pichia pastoris. Journal of Agricultural and Food Chemistry 54(21):8222-8228.

Kang, Y. N., et al., (2004) The roles of Glu186 and Glu380 in the catalytic reaction of soybean beta-amylase. Journal of Molecular Biology 339(5):1129-1140.

Kelly, Ronan M., Lubbert Dijkhuizen, and Hans Leemhuis (2009) Starch and alpha-glucan acting enzymes, modulating their properties by directed evolution. Journal of Biotechnology 140(3-4):184-193.

Kim, Y. K., and J. F. Robyt (1999) Enzyme modification of starch granules: in situ reaction of glucoamylase to give complete retention of D-glucose inside the granule. Carbohydrate Research 318(1-4):129-134.

Kirk, O., Borchert, T. V.and Fuglsang C. C. (2002) Industrial enzyme applications. Current Opinion in Biotechnology 13(4):345-351.

Kotting, O., et al., (2010) Regulation of starch metabolism: the age of enlightenment? Current Opinion in Plant Biology 13(3):321-329.

Kumari, A., et al., (2010) alpha-Amylase from germinating soybean (Glycine max) seeds - Purification, characterization and sequential similarity of conserved and catalytic amino acid residues. Phytochemistry 71(14-15):1657-1666.

Kuriki, T., and Imanaka T. (1999) The concept of the alpha-amylase family: Structural similarity and common catalytic mechanism. Journal of Bioscience and Bioengineering 87(5):557-565.

Lao, N. T., et al. (1999) An Arabidopsis gene encoding a chloroplast-targeted betaamylase. Plant Journa/20(5):519-527.

Lopez-Casado, Gloria, et al., (2008) Plant glycosyl hydrolases and biofuels: a natural marriage. Current Opinion in Plant Biology 11(3):329-337.

Lyko, F., et al., (1995) Signal sequence processing in rough microsomes. Journal of Biological Chemistry 270(34):1987319878.

Machovic, M., and Janecek, S. (2006a) The evolution of putative starch-binding domains. Febs Letters 580(27):63496356.
Machovic, M., and Janecek, S (2006b) Starchbinding domains in the post-genome era. Cellular and Molecular Life Sciences 63(23):2710-2724.

McCarter, J. D., and Withers S. G. (1994) Mechanisms of enzymatic glycoside hydrolysis. Current Opinion in Structural Biology 4(6):885-892.

Mitsui, T., and K. Itoh (1997) The alpha-amylase multigene family. Trends in Plant Science 2(7):255-261.

Motyan, Janos A., et al., (2011) Transglycosylation by barley alphaamylase 1. Journal of Molecular Catalysis B-Enzymatic 72(3-4):229-237.

Nirmala, M., and Muralikrishna G. (2003) Three alpha-amylases from malted finger millet (Ragi, Eleusine coracana, Indaf-15) purification and partial characterization. Phytochemistry 62(1):21-30.

Prabha, T. N., and Bhagyalakshmi M. (1998) Carbohydrate metabolism in ripening banana fruit. Phytochemistry 48(6):915919.

Prakash, O., and Jaiswal, N. (2010) AlphaAmylase: An Ideal Representative of Thermostable Enzymes. Applied Biochemistry and Biotechnology 160(8):2401-2414.

Ranki, H., and Sopanen, T. (1984) Secretion of alpha-amylase by the aleurone layer and the scutellum of germinating barleygrain. Plant Physiology 75(3):710-715.

Reilly, P. J. (1999) Protein engineering of glucoamylase to improve industrial performance - A review. Starch-Starke 51(8-9):269-274.

Richardson, T. H., et al., (2002) A novel, high performance enzyme for starch liquefaction - Discovery and optimization of a low $\mathrm{pH}$, thermostable alphaamylase. Journal of Biological Chemistry 277(29):26501-26507.

Robert, X., et al., (2003) The structure of barley alpha-amylase isozyme 1 reveals a novel role of domain $C$ in substrate recognition and binding: A pair of sugar tongs. Structure 11(8):973-984.

Rodriguez-Sanoja, R., N. Oviedo, and S. Sanchez (2005) Microbial starch-binding domain. Current Opinion in Microbiology 8(3):260-267.

Saitou, N., and Nei, M. (1987) The neighborjoining method - a new method for reconstructing phylogenetic trees. Molecular Biology and Evolution 4(4):406-425. 
BAJOPAS Volume 11 Number 2 December, 2018

Sauer, J., et al., (2000) Glucoamylase: structure/function relationships, and protein engineering. Biochimica Et Biophysica Acta-Protein Structure and Molecular Enzymology 1543(2):275-293.

Stam, M. R., et al., (2006) Dividing the large glycoside hydrolase family 13 into subfamilies: towards improved functional annotations of alpha-amylaserelated proteins. Protein Engineering Design \& Selection 19(12):555-562.

Stanley, D., Farnden, K. J. F.and MacRae E. A. (2005) Plant alpha-amylases: functions and roles in carbohydrate metabolism. Biologia 60:65-71.

Stanley, D., et al. (2002) Characterisation of putative alpha-amylases from apple (Malus domestica) and Arabidopsis thaliana. Biologia 57:137-148.

Tamura, Koichiro, et al. (2011) MEGA5: Molecular Evolutionary Genetics Analysis Using Maximum Likelihood, Evolutionary Distance, and Maximum Parsimony Methods. Molecular Biology and Evolution 28(10):2731-2739.

Tanaka, A., and E. Hoshino (2002) Calciumbinding parameter of Bacillus amyloliquefaciens alpha-amylase determined by inactivation kinetics. Biochemical Journal 364:635-63

Tanaka, A., and E. Hoshino (2003) Secondary calcium-binding parameter of Bacillus amyloliquefaciens alpha-amylase obtained from inhibition kinetics. Journal of Bioscience and Bioengineering 96(3):262-267.

Tibbot, B. K., D. W. S. Wong, and G. H. Robertson (2002) Studies on the Cterminal region of barley alpha-amylase 1 with emphasis on raw starch-binding. Biologia 57:229-238.

Vitale, A., and J. Denecke (1999) The endoplasmic reticulum - Gateway of the secretory pathway. Plant Cell 11(4):615628.

Walter, P., and G. Blobel (1981) Translocation of proteins across the endoplasmic reticulum III. Signal recognition protein (SRP) causes signal sequencedependent and site-specific arrest of chain elongation that is released by microsomal membranes. Journal of Cell Biology 91(2):557-561.

Warner, D. A., and C. A. Knutson (1991) Isolation of alpha-amylases and other starch degrading enzymes from endosperm of germinating maize. Plant Science 78(2):143-150.

Wegrzyn, T., et al. (2000) A novel alphaamylase gene is transiently upregulated during low temperature exposure in apple fruit. European Journal of Biochemistry 267(5):1313-1322.

Weihofen, A., et al. (2002) Identification of signal peptide peptidase, a presenilintype aspartic protease. Science 296(5576):2215-2218.

Yu, T. S., et al. (2005) Alpha-Amylase is not required for breakdown of transitory starch in Arabidopsis leaves. Journal of Biological Chemistry 280(11):9773-9779.

Zeeman, S. C., J. Kossmann, and A. M. Smith (2010) Starch: Its Metabolism, Evolution, and Biotechnological Modification in Plants. Annual Review of Plant Biology, Vol 61 61:209-234.

Zeeman, S. C., S. M. Smith, and A. M. Smith (2007a) The diurnal metabolism of leaf starch. Biochemical Journal 401:13-28.

Zeeman, Samuel C., et al. (2007b) Starch breakdown: recent discoveries suggest distinct pathways and novel mechanisms. Functional Plant Biology 34(6):465-473. 